\title{
Symptomless Host and Nonhost Responses of Paulownia (Paulownia spp.) to Olive-Defoliating Verticillium dahliae
}

Daniel Jiménez-Fernández and Concepción Olivares-García, College of Agriculture and Forestry (ETSIAM), University of Cordoba (UCO), Campus de Rabanales, Ctra. Madrid-Cádiz, km 396, 14071 Córdoba, Spain; José L. Trapero-Casas, Institute for Sustainable Agriculture (IAS), Spanish National Research Council (CSIC), Córdoba, Spain; Jaime Requena and Jesús Moreno, Plantas Continental, S.A., Rivero de Posadas, 14739 Posadas (Córdoba), Spain; and Rafael M. Jiménez-Díaz, ETSIAM-UCO, Campus de Excelencia Internacional Agroalimentario, ceiA3, and IAS-CSIC, Avda. Alameda del Obispo s/n, PO Box 4084, 14080, Córdoba, Spain

\begin{abstract}
Jiménez-Fernández, D., Olivares-García, C., Trapero-Casas, J. L., Requena, J., Moreno, J., and Jiménez-Díaz, R. M. 2015. Symptomless host and nonhost responses of paulownia (Paulownia spp.) to olive-defoliating Verticillium dahliae. Plant Dis. 99:962-968.

Symptomless host and nonhost responses of Paulownia spp. to olivedefoliating (D) Verticillium dahliae is reported for the first time. Two paulownia clones, Paulownia elongata 'PC-2' and P. elongata $\times$ P. fortunei 'PC-3', were inoculated with a $V$. dahliae isolate representative of the $\mathrm{D}$ pathotype by either root dip or stem injection with a conidial suspension, repeated transplanting to a $V$. dahliae-infested soil mixture, or root dip in the conidial suspension followed by transplanting to the infested soil mixture. 'Picual' olive and 'Sugar Baby' watermelon were included in all experiments as susceptible standards to show that the inoculation procedures and incubation conditions were successful. Plants were incubated under conditions optimal for Verticillium wilt that caused severe disease in 'Picual' olive and 'Sugar Baby' watermelon in the growth chamber, shade house, and field microplots for 30 to 57 weeks

in three independent experiments. No foliar symptoms developed on paulownia, whose stems were found free of $V$. dahliae both by isolation on semiselective NP-10 medium as well as by a nested-polymerase chain reaction assay using total genomic DNA from inoculated plants that effectively detected $\mathrm{D} V$. dahliae in olive stems. $V$. dahliae was isolated to a limited extent from roots of PC-3 paulownia plants after 30 weeks of growth in the infested soil mixture but not from those that were rootdip inoculated or from PC-2 plants regardless the method of inoculation. The symptomless host and nonhost responses of Paulownia spp. to D $V$. dahliae may have practical applications in the use of fertile soils in southern Spain, particularly in those that are highly infested with the highly virulent $\mathrm{D}$ pathotype, as well as a replacement crop for Verticillium wilt-affected olive orchards in that region.
\end{abstract}

Paulownia (Paulownia spp.) is a medium-sized, fast-growing (up to $5 \mathrm{~m}$ a year) woody plant within the botanical family Scrophulariaceae (Lucas Borja et al. 2009). The genus Paulownia comprises nine species native to East Asia, though they are widely distributed in China, where they are intercropped on 2.5 million ha of farmland (Lyons 1993; Zhu et al. 1986). Besides their very rapid growth rate, Paulownia spp. have C4 metabolism and are characterized by soft, low-density, and highquality timber (Zhu et al. 1986). This has made Paulownia spp. suitable to be grown commercially in Australia, China, India, Japan, Korea, North America, South America, and New Zealand (Bassett 1998; Hiruki 1999; Mehrotra 1997). Paulownia trees have recently been introduced in Spain as a new plantation timber species aimed to be used as an alternative energy source and for climate change mitigation. In particular, early studies showed that Paulownia elongata and the hybrid $P$. elongata $\times P$. fortunei thrive well under the Mediterranean environment in central (Castilla-La Mancha) and southern Spain (Andalusia) (Lucas Borja et al. 2009) (J. Moreno and J. Requena, unpublished).

Verticillium dahliae Kleb. is a vascular-colonizing, soilborne mitosporic fungus able to survive in the soil by means of melanized microsclerotia without a host for at least 14 years (Pegg and Brady 2002; Wilhelm 1955). V. dahliae also is characterized by a wide host range and high genetic and virulence diversity in its populations that make Verticillium wilts among the diseases most difficult to manage (Collado-Romero et al. 2006; Inderbitzin et al. 2011; Jiménez-Díaz et al. 2006; Pegg and Brady 2002). V. dahliae is likely to have one of the broadest host ranges of any fungal plant pathogen, which

Corresponding author: R. M. Jiménez-Díaz; E-mail: ag1jidir@uco.es

Accepted for publication 2 January 2015.

http://dx.doi.org/10.1094/PDIS-09-14-0883-RE

(C) 2015 The American Phytopathological Society includes over 400 susceptible annual herbaceous crops and weeds as well as fruit, landscape and ornamental trees, and shrubs. This symptomatic host range can be made even larger if the recently shown ability of $V$. dahliae to develop asymptomatic, endophytic infections is taken into account (Malcolm et al. 2013; Pegg and Brady 2002). However, there are no records of infection of Paulownia spp. by $V$. dahliae among the several published lists of tree hosts of this pathogen (Hiemstra 1998; Maul 1999; McCain et al. 1981; Pataky 1997). In Andalusia, planting of paulownia would be of much use for replacing old, unproductive olive groves in addition of exploiting forest land. However, that use would be at risk if paulownia is susceptible to Verticillium wilt caused by $V$. dahliae, and particularly to a highly virulent olive-defoliating (D) strain in vegetative compatibility group 1A (VCG1A/D lineage) that has become widespread in that region and currently is causing devastation in young and old olive orchards (Jiménez-Díaz et al. 2011, 2012; Milgroom et al. 2014).

The main objective of this study was to determine whether a $V$. dahliae isolate representative of the $\mathrm{D}$ pathotype prevailing in Andalusia, southern Spain can infect and be pathogenic to paulownia clones that are well adapted and can be grown commercially in that region.

\section{Materials and Methods}

Plant material. Certified 6-month-old plants $(10 \mathrm{~cm}$ in height $)$ of paulownia clones 'PC-2' (P. elongata) and 'PC-3' (P. elongata $\times$ $P$. fortunei) and 4-month-old $V$. dahliae-free 'Picual' olive plants (20 cm in height) were used. These plants were propagated by Plantas Continental, S.A. (Posadas, Córdoba, Spain). Paulownia plants were axenically micropropagated from axillary buds and further rooting in an autoclaved (twice at $121^{\circ} \mathrm{C}$ for $1.5 \mathrm{~h}$ ) potting mixture (peat/sand, $2: 1, \mathrm{vol} / \mathrm{vol}$ ). Olive plants were propagated by rooting leafy stem cuttings in the autoclaved potting mixture under mist conditions in plastic tunnels. Before use in experiments, plants were further grown in plastic pots with pasteurized soil in the greenhouse for 2 months, at which time they were $25 \mathrm{~cm}$ (paulownia) and $40 \mathrm{~cm}$ (olive) in height. 
In addition, V. dahliae-free seed of 'Sugar Baby' watermelon (Semillas Fitó, Barcelona, Spain) were used in the study. Both the olive and watermelon cultivars were purposely chosen because they are known to be highly susceptible to V. dahliae VCG1A/D (Bhat and Subbarao 1999; Jiménez-Díaz et al. 2012; López-Escudero et al. 2004).

$V$. dahliae isolates and inoculum production. $V$. dahliae isolates V138I and V1558I, representatives of the D and nondefoliating (ND) pathotypes in Andalusia, respectively, were used in the experiments. Those isolates have been characterized to pathotype by both pathogenicity assays and DNA markers (Jiménez-Díaz et al. 2011; MercadoBlanco et al. 2002, 2003), as well as to VCG (Collado-Romero et al. 2006; Jiménez-Díaz et al. 2011). Isolates V138I and V1558I belong to VCG1A and VCG2A, respectively. Single-spore cultures of those isolates are deposited in the culture collection of the Department of Crop Protection, Institute for Sustainable Agriculture, Spanish National Research Council, Córdoba, Spain. Isolates were stored by covering cultures on plum-extract agar in test tubes (Talboys 1960) with liquid paraffin (Bejarano-Alcázar et al. 1996) at $4{ }^{\circ} \mathrm{C}$ in the dark. Active cultures of isolates were obtained by placing small agar plugs from stock cultures on chlortetracycline-amended water agar (1 liter of distilled water, $20 \mathrm{~g}$ of agar, and $30 \mathrm{mg}$ of chlortetracycline) and further subculturing on potato dextrose agar (PDA; Difco Laboratories, Detroit). Cultures on PDA were grown for 7 days at $24^{\circ} \mathrm{C}$ in the dark and used to increase inoculum. For experiments, inocula consisted of conidial suspensions or infested cornmeal-sand mixture (CMS) (Nene and Haware 1980). Conidia were from cultures in potato-dextrose broth incubated at $125 \mathrm{rpm}$ on an orbital shaker (Adolf Kühner AG, Birsfelden, Switzerland) at $24^{\circ} \mathrm{C}$ in the dark for 7 days. Conidia in the liquid cultures were filtered through eight layers of sterile cheesecloth and inoculum concentration was adjusted to $2 \times 10^{7}$ conidia $\mathrm{ml}^{-1}$ with sterile water using a hemocytometer. Inocula in CMS were produced only for the D isolate V138I because of the wider distribution, higher virulence, and epidemiological importance on olive of the D pathotype compared with the ND pathotype (Jiménez-Díaz et al. 2011; Mercado-Blanco et al. 2002, 2003; Navas-Cortés et al. 2008). CMS inocula were produced in
Erlenmeyer flasks containing $400 \mathrm{~g}$ of autoclaved (twice at $121^{\circ} \mathrm{C}$ for $1.5 \mathrm{~h}$ ) mixture incubated at $24 \pm 1^{\circ} \mathrm{C}$ in the dark for 4 weeks. The inoculum density of $V$. dahliae in the infested CMS was determined by dilution-plating assay on semiselective NP-10 medium (Kabir et al. 2004). Infested CMS was thoroughly mixed with a pasteurized soil mixture (clay loam/peat, $2: 1$, vol/vol) to reach an inoculum density of $V$. dahlia of approximately $1 \times 10^{6} \mathrm{CFU} g$ of soil ${ }^{-1}$.

Pathogenicity assays. Three experiments (I to III) were conducted to determine the ability of $\mathrm{D} \mathrm{V}$. dahliae to infect and cause disease to paulownia. Olive and watermelon were included in experiments as $V$. dahliae-susceptible controls to ensure that virulence of inocula and incubation conditions were adequate for successful infection and disease on known host plants. Plants were inoculated either by transplanting to the infested soil mixture (experiment I), root dip or stem injection with a conidial suspension (experiment II), or jointly by root dip followed by transplanting to the infested soil mixture (experiment III), depending on the experiment (Table 1). Paulownia plants were also stem-injection inoculated with ND isolate V1558I in experiment II. There was no intention to comparatively test the different procedures used for inoculation of paulownia; rather, we aimed to ensure that they did not influence the response of paulownia to inoculation, as indicated by the response of known susceptible plants. Plants were grown in disinfested plastic pots and incubated in a Conviron growth chamber adjusted to $24 \pm 1{ }^{\circ} \mathrm{C}$ light and darkness, 60 to $70 \%$ relative humidity (RH), and a 14-h photoperiod of fluorescent light of $360 \mu \mathrm{E} \mathrm{m}^{-2} \mathrm{~s}^{-1}$ for 4 to 22 weeks. After this, plants were transplanted and moved to one of three locations, depending on the experiment (see below). Plants were watered every 1 to 2 days as needed and fertilized weekly with $50 \mathrm{ml}$ of Hoagland's nutrient solution (Hoagland and Arnon 1950).

For experiment I, plants of $P$. elongata clone PC- 2 were inoculated by transplanting to $\mathrm{D} V$. dahliae V138I-infested soil mixture twice in a sequence. Plants were first grown in 1.5 -liter pots ( 13 by 11 by $10 \mathrm{~cm}$ ) filled with the infested mixture in the growth chamber for 22 weeks; then, plants were transplanted in 3 -liter pots $(16.5 \mathrm{~cm}$ in diameter by $15.5 \mathrm{~cm}$ in height) filled with the same $V$. dahliae-

Table 1. Reaction of plant species to inoculation with olive-defoliating (V138I) and -nondefoliating (V1558I) isolates of Verticillium dahliae

\begin{tabular}{|c|c|c|c|c|c|c|c|}
\hline \multirow[b]{2}{*}{ Experiment, plant species ${ }^{b}$} & \multirow[b]{2}{*}{ Isolate } & \multirow[b]{2}{*}{ Inoculation method } & \multicolumn{3}{|c|}{ Disease reaction } & \multicolumn{2}{|c|}{$\begin{array}{l}\text { V. dahliae } \\
\text { isolationa }^{\mathrm{a}}\end{array}$} \\
\hline & & & Incubation $^{\mathrm{c}}$ & Incidence $(\%)^{d}$ & $\overline{\text { Severity/duration }}{ }^{\mathrm{e}}$ & Root & $\overline{\text { Stem }}$ \\
\hline \multicolumn{8}{|l|}{ I } \\
\hline PC-2 Paulownia & V138I & Infested soil & nd & 0 & $0 / 47$ & nd & - \\
\hline Picual olive & V138I & Infested soil & 28 & 100 & $3.5 / 9$ & nd & + \\
\hline \multicolumn{8}{|l|}{ II } \\
\hline \multirow[t]{3}{*}{ PC-2 Paulownia } & V138I & Root dip & nd & 0 & $0 / 57$ & - & - \\
\hline & $\ldots$ & Stem injection & nd & 0 & $0 / 57$ & - & - \\
\hline & V1558I & Stem injection & nd & 0 & $0 / 57$ & - & - \\
\hline \multirow[t]{2}{*}{ Sugar Baby watermelon } & V138I & Root dip & 2 & 100 & $3.6 / 2$ & nd & + \\
\hline & V138I & Stem injection & 2 & 90 & $1.8 / 3$ & nd & + \\
\hline Picual olive & V138I & Root dip & 31 & 100 & $3.2 / 11$ & nd & + \\
\hline \multicolumn{8}{|l|}{ III } \\
\hline \multirow[t]{2}{*}{ PC-3 Paulownia } & V138I & Infested soil & nd & 0 & $0 / 30$ & + & - \\
\hline & $\ldots$ & $\begin{array}{l}\text { Root dip+ } \\
\text { Infested soil }\end{array}$ & nd & 0 & $0 / 30$ & + & - \\
\hline \multirow[t]{2}{*}{ Sugar Baby watermelon } & V138I & Infested soil & 35 & 70 & $2.3 / 8$ & nd & + \\
\hline & $\ldots$ & $\begin{array}{l}\text { Root dip+ } \\
\text { Infested soil }\end{array}$ & 35 & 70 & $2.3 / 8$ & nd & + \\
\hline \multirow[t]{2}{*}{ Picual olive } & V138I & Infested soil & 21 & 60 & $2.7 / 8$ & nd & + \\
\hline & $\ldots$ & $\begin{array}{l}\text { Root dip+ } \\
\text { Infested soil }\end{array}$ & 21 & 100 & $2.9 / 8$ & nd & + \\
\hline
\end{tabular}

a Isolations were done on NP-10 medium at the end of experiments using eight root pieces and 12 stem fragments from each paulownia plant and four stem fragments from each of olive and watermelon plants. Symbols: $+=$ colonies of $V$. dahliae developed from plated tissue fragments and $-=$ no colony of $V$. dahliae developed from platted tissue fragments; nd = not done.

b Ten plants of each of paulownia clones PC-2 (Paulownia elongata) and PC-3 (P. elongata $\times$ P. fortunei), 'Picual' olive, and 'Sugar Baby' watermelon were inoculated with monoconidial $V$. dahliae isolates V138I and V1558I and incubated under different environmental conditions (see Materials and Methods section for details).

${ }^{\mathrm{c}}$ Incubation period (days) = time taken for disease severity $>0$; nd = not determined because symptoms did not develop in paulownia plants.

${ }^{\mathrm{d}}$ Percentage of plants showing foliar symptoms.

e Severity/duration of experiment (weeks). Mean severity of foliar symptoms at the end of experiment assessed on a 0 -to-4 rating scale according to the percentage of affected leaves and twigs ( $0=$ no symptoms; $1=1$ to $33,2=34$ to 66 , and $3=67$ to $100 \%$ affected; and $4=$ dead plant). Each value is the mean of 10 plants 
infested mixture and grown in a mesh-covered shade house $(30 \%$ shade provided) for an additional 25 weeks. Picual olive plants were inoculated only once by transplanting to the infested soil mixture and incubating in the growth chamber for 9 weeks, at which time severe disease had already developed (see below). Plants grown in noninfested CMS mixed with the pasteurized soil mixture at the same rate as infested CMS served as controls.

For experiment II, plants of $P$. elongata clone PC-2 were inoculated by either (i) the root-dip or stem-injection methods with $\mathrm{D}$ $V$. dahliae V138I at $2 \times 10^{7}$ conidia $\mathrm{ml}^{-1}$ or (ii) stem injection with ND $V$. dahliae V1558I at $2 \times 10^{7}$ conidia $\mathrm{ml}^{-1}$. For root-dip inoculation, plants were uprooted from the potting substrate and their roots were washed in tap water to remove substrate residues, slightly trimmed, and dipped in the conidial inoculum for $20 \mathrm{~min}$. Plants then were transplanted to plastic pots filled with the pasteurized soil mixture (one plant per pot). For stem-injection inoculation, stems were punctured at two opposite points at the base of the first and second internodes and one 5- $\mu$ l drop of conidial inoculum was deposited in each hole (Bejarano-Alcázar et al. 1996; López-Escudero et al. 2007). Control plants were treated similarly with sterile distilled water. Inoculated and control plants were incubated in the growth chamber adjusted to the same conditions as above for 4 weeks, then in a greenhouse adjusted to $23.5 \pm 5^{\circ} \mathrm{C}$ and $66.6 \pm 5.8 \% \mathrm{RH}$ for 16 weeks, and finally transplanted to drip-irrigated field microplots (1.25 by $1.25 \mathrm{~m}, 50 \mathrm{~cm}$ deep), where they grew for 37 weeks at $14.8 \pm 5.7^{\circ} \mathrm{C}$ and $73.3 \pm 13.7 \%$ RH. 'Picual' olive and 'Sugar Baby' watermelon served as susceptible controls in this experiment. Olive plants were root-dip inoculated with D V. dahliae V138I at $2 \times 10^{7}$ conidia $\mathrm{ml}^{-1}$, as for paulownia. Watermelon plants (4 weeks old) were inoculated either by the root-dip or stem-injection methods with D V. dahliae V138I at $2 \times 10^{7}$ conidia $\mathrm{ml}^{-1}$, as for paulownia. Watermelon plants were obtained by sowing surface-disinfested $(2 \%$ $\mathrm{NaOCl}$ for $3 \mathrm{~min}$ ), germinated (length of radicle $=1$ to $2 \mathrm{~cm}$ ) seed in pasteurized soil in 1.5-liter pots and growing them in the growth chamber for 4 weeks. Control plants were treated similarly with sterile distilled water. Root-dip inoculated and control plants were transplanted to plastic pots filled with the pasteurized soil mixture. Watermelon and olive plants were incubated in the growth chamber for 2 to 3 weeks and 4 weeks, respectively, but olive plants were further incubated in the greenhouse for 7 weeks, as for paulownia plants. Inoculated olive and watermelon plants had already developed severe disease symptoms by these times of incubation (see below).

For experiment III, plants of hybrid P. elongata $\times$ P. fortunei clone PC-3 and 'Picual' olive were inoculated once by transplanting to D $V$. dahliae V138I-infested soil mixture, as for experiment I; or inoculated twice in a sequence, first by root dip in a suspension of $\mathrm{D}$ V. dahliae V138I at $2 \times 10^{7}$ conidia $\mathrm{ml}^{-1}$ followed by transplanting to the soil mixture infested with the same isolate. In addition, 'Sugar Baby' watermelon was inoculated by sowing surface-disinfested, germinated seed in the D V. dahliae V138I-infested soil mixture in 1.5-liter pots. Control plants were treated similarly as inoculated plants, except for the absence of inoculum. Inoculated and control paulownia, olive, and watermelon plants were incubated in the growth chamber for 8 weeks; thereafter, paulownia plants were further incubated in the greenhouse adjusted to $20 \pm 5^{\circ} \mathrm{C}$ and $70.5 \pm 6.3 \% \mathrm{RH}$ for 4 weeks and, finally, transplanted to field microplots where they grew for 18 weeks at $17.5 \pm 5.6^{\circ} \mathrm{C}$ and $66.1 \pm 14.4 \% \mathrm{RH}$. Olive and watermelon plants had developed severe disease by 8 weeks of incubation (see below).

Experiments consisted of a one-way treatment design with 10 and 5 replicated pots (one plant per pot) for inoculated and noninoculated plants, respectively, in a completely randomized design. Disease reaction was assessed by the incidence (percentage) and severity of foliar symptoms. Symptoms were assessed on individual plants on a 0 -to-4 rating scale according to the percentage of affected leaves and twigs $(0=$ no symptoms; $1=1$ to $33,2=34$ to 66 , and $3=67$ to $100 \%$ affected; and $4=$ dead plant) at 2 - to 3 -day intervals during the incubation period in the growth chamber and at 1-week intervals while grown in the shade house and microplots. Also, the height of the main stem of paulownia plants was measured at the time of inoculation and the end of experiments II and III. In addition, the stem diameter of plants $10 \mathrm{~cm}$ above the soil line was measured for experiment III. Data for plant growth were subjected to standard analysis of variance using Statistix v10.0 (NH Analytical Software, Roseville, $\mathrm{MN})$. Treatment means for each inoculation method were compared with the noninoculated control using the Dunnett's test at $P<0.05$.

Paulownia infection and colonization. Upon termination of experiments, attempts were made to isolate the pathogen on NP-10, a semiselective medium for isolation of $V$. dahliae (Kabir et al. 2004), from root and stem segments of each paulownia plant to determine the extent of infection and colonization by $V$. dahliae. The whole root system and stem (without leaves) of a plant were washed thoroughly under tap water for $30 \mathrm{~min}$, blotted dry between filter paper, then cut into 1-cm-long pieces. Eight 1-cm-long root pieces arbitrarily chosen from different radial and vertical sections of the root ball were surface disinfested in $0.5 \% \mathrm{NaClO}$ for $2 \mathrm{~min}$, rinsed twice in sterile water, blotted dry between autoclaved filter paper, and plated on the medium in petri dishes. The main stem of a plant was equally divided into three sections representative of lowermost (soil line to 25 to $40 \mathrm{~cm}$ height), medium (between 25 to 40 and 50 to $80 \mathrm{~cm}$ height) and upper (between 50 to 80 and 75 to $120 \mathrm{~cm}$ height) zones, the bark was aseptically removed, and four 1-cm-long pieces from each zone were surface disinfested in $0.5 \% \mathrm{NaClO}$ for $1 \mathrm{~min}$, rinsed twice in sterile water, blotted dry, and plated on the medium in petri dishes. To ensure physical contact of the vascular stem tissues with the medium, each of the stem pieces were split longitudinally into two halves and placed so that the cut surface came into contact with the medium. Cultures were incubated at $25^{\circ} \mathrm{C}$ in the dark for 21 days. Isolations were also made from stems of olive and watermelon plants, as described above for paulownia. Four 1-cm-long pieces representative of the total length of stems were washed and blotted dry, and the bark was aseptically removed (olive only), disinfested, plated, and incubated as described. Colonies of $V$. dahliae were identified by microscopic observations of verticillate conidiophores and formation of microsclerotia (Inderbitzin et al. 2011). Data from the paulownia stem isolations of the pathogen were used to calculate the intensity of vascular colonization according to a colonization index (CI): $\mathrm{CI}=\sum \mathrm{Ni} / \mathrm{Nj} \times$ 100 , where $\mathrm{Ni}$ is the number of plated stem pieces from which $V$. dahliae was isolated and $\mathrm{Nj}$ is the total number of stem pieces plated.

Paulownia stem pieces sampled for isolations in experiment III were used also for a nested polymerase chain reaction (PCR) assay to further confirm whether incipient infections by $V$. dahliae of paulownia plants might have gone undetected by isolation on NP-10. For this assay, total genomic DNA extracted from stem pieces was amplified using primers DB19, DB22, and espdef01 that are effective for in planta detection of D V. dahliae in olive roots and stems (Mercado-Blanco et al. 2003). Total genomic DNA extracted from stems of symptomatic Picual olive grown for 8 weeks in the D-infested soil mixture in experiment III was used as positive control. This assay yielded a $V$. dahliae-specific polymorphic band of 523 or $539 \mathrm{bp}$ for ND and D isolates, respectively, in the first round of amplification, and a D-specific 334-bp amplicon in the second round of amplification (Mercado-Blanco et al. 2003). Total genomic DNA was extracted from stems using the Illustra DNA extraction kit Phytopure (GE Healthcare, UK) and the Fast Prep System Bio 101 (Qbiogene, Illkirch, France) according to Jiménez-Fernández et al. (2010). DNA quality was assessed by gel electrophoresis and staining with ethidium bromide. All DNA samples were quantified using a Tecan Safire fluorospectrophotometer (Tecan Spain, Barcelona, Spain) (Landa et al. 2007). DNA was diluted with sterile ultrapure water to $30 \mathrm{ng} / \mu \mathrm{l}$ as appropriate. Amplification reactions for the first round of amplification (final volume $25 \mu \mathrm{l}$ ) consisted of $2.5 \mu \mathrm{l}$ of $10 \times$ reaction buffer $\left(160 \mathrm{mM}\left(\mathrm{NH}_{4}\right)_{2} \mathrm{SO}_{4}, 670 \mathrm{mM}\right.$ Tris- $\mathrm{HCl}[\mathrm{pH}$ 8.8 at $25^{\circ} \mathrm{C}$ ], and $0.1 \%$ Tween-20), $0.4 \mu \mathrm{M}$ each of primers DB19 and DB22, $200 \mu \mathrm{M}$ each dNTP, $0.75 \mathrm{U}$ of BioTaq DNA polymerase (Bioline), $2.5 \mathrm{mM} \mathrm{MgCl}_{2}$, and $1 \mu$ l of template DNA (30 ng). Reaction conditions were denaturation at $94^{\circ} \mathrm{C}$ for $4 \mathrm{~min}$; followed by 30 cycles of $1 \mathrm{~min}$ of annealing at $58^{\circ} \mathrm{C}$, extension for $1 \mathrm{~min}$ at $72^{\circ} \mathrm{C}$, and denaturation for $1 \mathrm{~min}$ at $94^{\circ} \mathrm{C}$; and a final extension step of $6 \mathrm{~min}$. The second round of amplification was carried out using primer pairs DB19/espdef01. In this PCR round, $0.5 \mu 1$ of the product from the first 
round of amplification was transferred to a new 200- $\mu$ l PCR tube with an additional $24.5 \mu l$ of reaction mixture for the second amplification reaction. Conditions and parameters used in this round of amplification were the same as for the first round, except that only 25 cycles were run with the annealing temperature set at $62^{\circ} \mathrm{C}$ for $30 \mathrm{~s}$, and the final extension step was $10 \mathrm{~min}$. To determine if the PCR reaction was affected by inhibitors from the paulownia extraction, different DNA concentrations from $\mathrm{D} V$. dahliae mycelium $(5$ and $0.05 \mathrm{ng} / \mu \mathrm{l})$ were added to several dilutions of paulownia stem DNA (1- to 10-fold dilutions). The nested-PCR assays were repeated twice. In addition, to check for the absence of PCR inhibitors from paulownia stem tissues, DNA samples were amplified in PCR assays using universal primers internal transcribed spacer (ITS) 4 and ITS5 (White et al. 1990) and conditions described by Landa et al. (2007). Amplifications were performed in a PTC 100 (MJ Research Inc., Watertown, MA) thermocycler. Amplification products were separated by electrophoresis in $1 \%$ agarose gels in $1 \times$ Tris-acetate-EDTA buffer for 60 to $90 \mathrm{~min}$ at $90 \mathrm{~V}$, stained with ethidium bromide, and visualized under UV light. The gene ruler DNA ladder mix (Fermentas, St. Leon-Rot, Germany) was used for electrophoresis.

\section{Results}

Disease reaction of paulownia, olive, and watermelon plants to $\boldsymbol{V}$. dahliae isolates. No symptoms developed in noninoculated plants of olive, paulownia, and watermelon. Results for inoculated $V$. dahliaesusceptible controls olive and watermelon are summarized in Table 1. In Picual olive, symptoms started to develop by 21 to 31 days after transplanting to infested soil mixture or root-dip inoculation, respectively. Symptoms consisted of early dropping of asymptomatic, green leaves from individual twigs that eventually resulted in complete defoliation, necrosis, and death of the plant, which are typical for the defoliating syndrome caused by D $V$. dahliae (Fig. 1) (Jiménez-Díaz et al. 2012; Navas-Cortés et al. 2008). Disease incidence reached $100 \%$ for experiments I (transplanting to infested soil mixture) and II (root-dip inoculation) by 9 to 11 weeks after inoculation, respectively, at which time the mean symptom severity ranged from 3.2 to 3.5 within a 0 -to-4 rating scale. In experiment III, disease incidence was 60 and $100 \%$ by 8 weeks after inoculation by transplanting to the infested soil mixture or root dip then transplanting to infested soil mixture, respectively, with the severity of symptoms averaging 2.7 and 2.9. V. dahliae was isolated from $100 \%$ of sampled stem tissues in all experiments (Table 1).

Watermelon plants wilted by 2 and 35 days after inoculation with D $V$. dahliae, depending on the inoculation procedure in experiments II and III, respectively. Disease reaction was more severe in experiment II, in root-dip inoculated plants (100\% disease incidence, 3.6 mean symptom severity by 2 weeks after inoculation) than in plants inoculated by stem injection ( $90 \%$ disease incidence, 1.8 mean symptom severity by 3 weeks after inoculation). In experiment III, inoculation by sowing germinated seed in the infested soil mixture or root dip then transplanting to infested soil mixture gave rise to $70 \%$ disease incidence and 2.3 mean severity of symptoms by 8 weeks after inoculation. All symptomatic tissue yielded $V$. dahliae from attempted isolations (Table 1).

No foliar symptoms developed on paulownia plants regardless of differences in clones, $V$. dahliae isolates, method of inoculation, incubation conditions, or long-term incubation period (Fig. 1; Table 1). In addition, we failed to isolate $V$. dahliae from either roots or stems of PC-2 plants by 57 weeks after root-dip or stem-injection inoculations with D and ND isolates in experiment II, as well as from stems of PC-2 plants by 47 weeks after transplanting to a soil mixture heavily infested with the same D isolate in experiment I (isolations from roots not done). Similarly, we did not isolate $V$. dahliae from stems of PC-3 plants by 30 weeks after inoculation with the $\mathrm{D}$ isolate by transplanting to the infested soil mixture or by root dip in a conidia suspension of the isolate and transplanting to the infested mixture in a sequence in experiment III (Table 1). Moreover, the nested-PCR assay carried out using total genomic DNA extracted from the same paulownia stem pieces yielded no amplification product for the $\mathrm{D}$ $V$. dahliae-specific amplicon. Conversely, the D-specific 334-bp PCR product was amplified from DNA extracted from stem tissues of affected olive plants. However, the 334-bp D-specific product was amplified from all combinations of paulownia stem extractions spiked with DNA of the $V$. dahliae D isolate, indicating that there was no PCR inhibition by the paulownia extract (Fig. 2). DNA quality and absence of PCR inhibitors were determined by amplification of the ITS1-5.8S-ITS2 regions of the ribosomal DNA by means of a PCR assay using the universal primer pair ITS4/ITS5 according to Landa et al. (2007) (data not shown). However, isolations from the root system of those same plants in experiment III yielded $V$. dahliae in all of them, the mean index of root colonization being 44.8 and $43.7 \%$ for plants transplanted to the infested soil mixture or inoculated by root dip followed by transplanting to that mixture, respectively (Table 1). Colonies of the fungus forming from platted root pieces did not show a polar pattern of growth from the cut ends but, rather, had a round appearance developing from the pieces surface.

Growth of paulownia plants inoculated with $V$. dahliae. Steminjection inoculation of PC-2 plants with a conidial suspension of D and ND $V$. dahliae isolates did not significantly influence $(P \geq 0.05)$ plant stem height by the end of experiment II, 57 weeks after inoculation (Fig. 3). However, inoculation of PC-2 plants by root dip in a conidial suspension of same D isolate significantly reduced by $53 \%$ the mean stem height compared with that of noninoculated control plants $(P<0.05)$ (Fig. 3). Interestingly, that pattern of effect changed when PC-3 plants were inoculated by transplanting to the soil mixture infested with the $\mathrm{D}$ isolate, or by root dip in a conidial suspension of this isolate and subsequent transplanting to the infested mixture. These two inoculation methods gave rise to a statistically significant $(P<0.05) 42$ and $35 \%$ increase in stem height, respectively, compared with that of noninoculated control plants (Fig. 3). That growth promotion effect was also expressed in the stem diameter, which was significantly $(P<0.05)$ increased by 30 and $34 \%$,

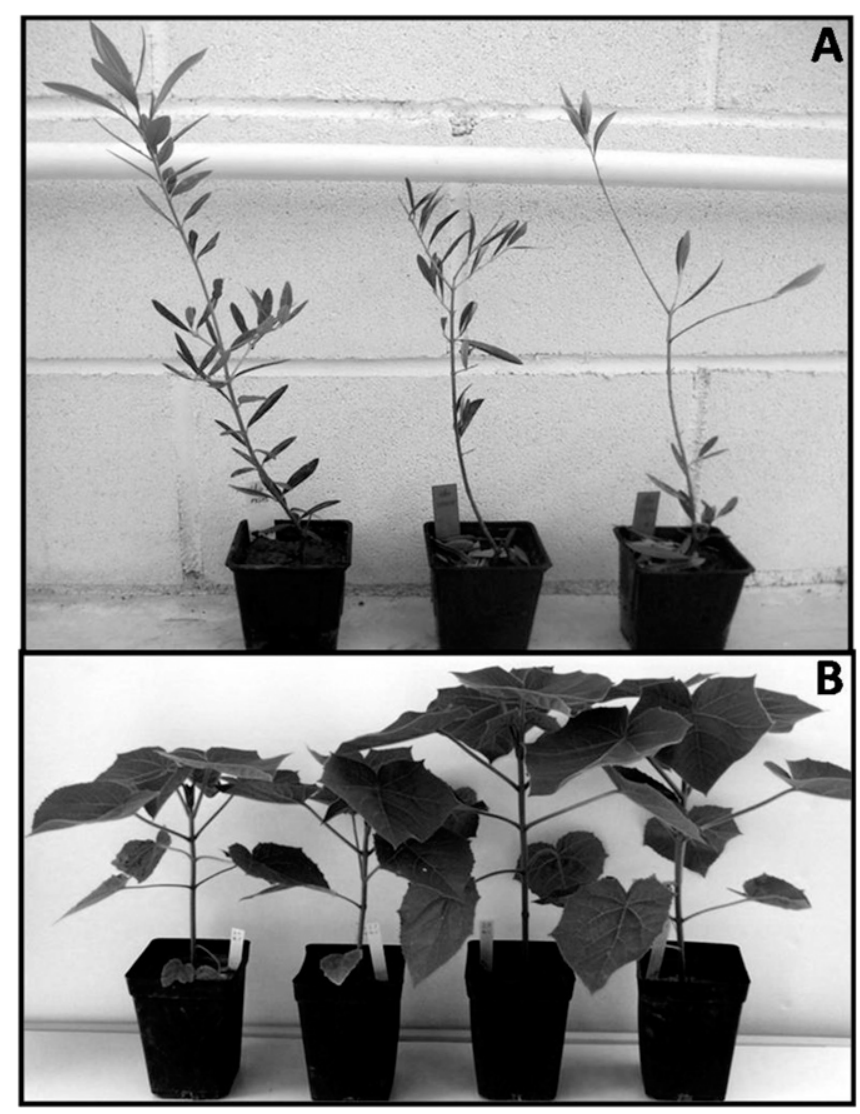

Fig. 1. Disease reaction of paulownia and olive plants 8 weeks after inoculation with defoliating Verticillium dahliae in experiment III. A, Picual olive. From left to right: noninoculated control, plant transplanted to infested soil mixture, and plant root-dip inoculated then transplanted to infested soil mixture. Note defoliation characteristic of the defoliating syndrome in olive. B, PC-3 paulownia plants. From left to right, two for each of: noninoculated control and plant root-dip inoculated then transplanted to infested soil mixture. Note the increased stem height in inoculated, symptomless plants compared with the control. 
respectively, in plants transplanted to the infested soil mixture or by root dip in a conidia suspension prior to transplanting to that soil mixture compared with the stem diameter of noninoculated controls (data not shown).

\section{Discussion}

Knowledge regarding susceptibility of a plant to either infection or disease caused by $V$. dahliae is of importance in the design of crop rotations for disease management. In the present study, two paulownia clones, each representative of different Paulownia spp., grew with symptomless foliage for up to 1 year after inoculation with a highly virulent $\mathrm{D}$ strain of $V$. dahliae using a range of inoculation methods, inoculation densities, and incubation conditions that caused severe disease in 'Picual' olive and 'Sugar Baby' watermelon in this present work, as well as in these and other susceptible plants in previous studies (Bejarano-Alcázar et al. 1996; Bhat and Subbarao

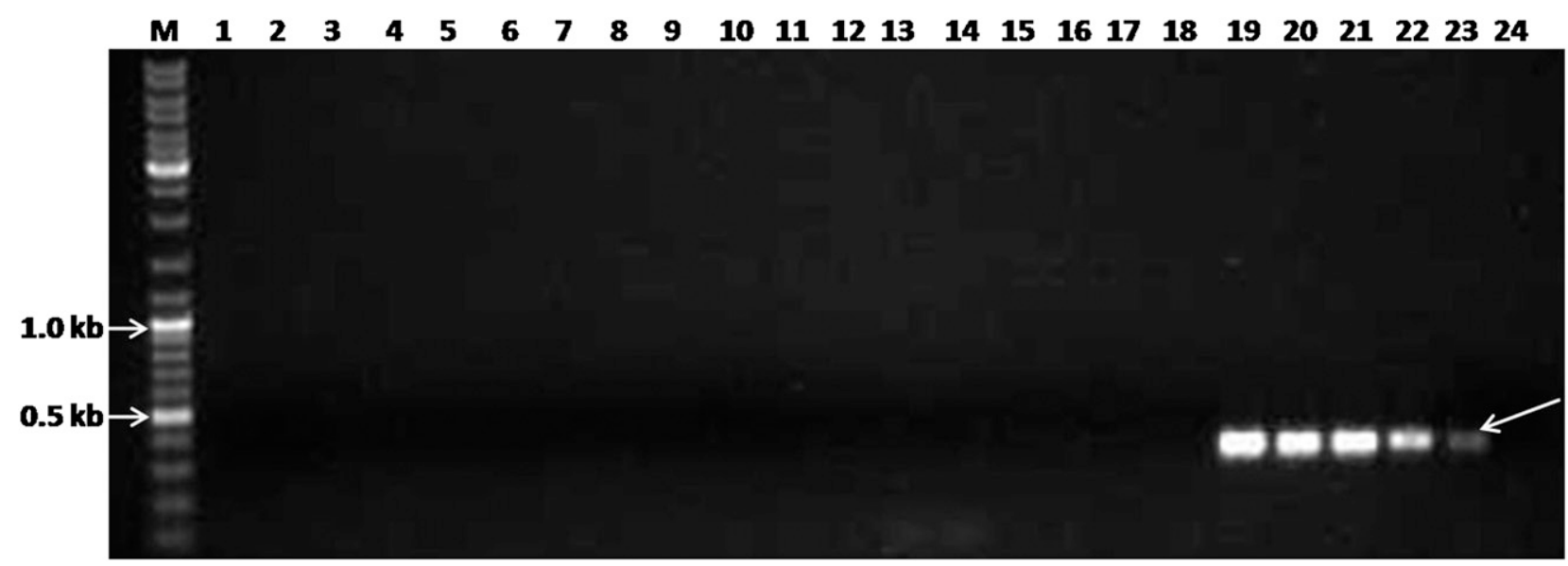

334 bp

Fig. 2. Gel electrophoresis of the second round of the nested polymerase chain reaction assay using primers DB19 and espdef01and total genomic DNA extracted from stems of PC-3 paulownia plants 30 weeks after inoculation with defoliating (D) Verticillium dahliae V138I by root dip in $2 \times 10^{7} \mathrm{conidia} \mathrm{ml}^{-1}$, or by root dip in the conidia suspension then transplanting to a soil mixture infested with $1 \times 10^{6} \mathrm{CFU} \mathrm{g} \mathrm{soil}^{-1}$ in experiment III. This assay yields a D V. dahliae-specific 334-bp amplicon (Mercado-Blanco et al. 2003). Lane M, gene-ruler DNA ladder mix (Fermentas, St. Leon-Rot, Germany); lanes 1-6, total genomic DNA from stems of plants grown in D V. dahliae-infested soil; lanes 7 and 8 , total genomic DNA from stem of plants grown in noninfested soil; lane 9, empty; lanes 10-15, total genomic DNA from stems of plants inoculated by root dipping and transplanting to infested soil mixture; lanes 17 and 18, total genomic DNA from stems of control plants of the root dip + transplanting inoculation treatment; lane 19, paulownia stem DNA (30 ng/ $\mu$ l) + V. dahliae

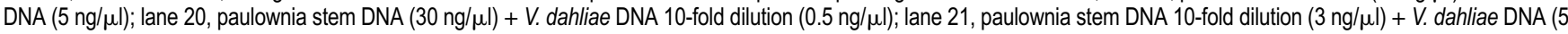
$\mathrm{ng} / \mu \mathrm{l})$; lane 22, paulownia stem DNA 10-fold dilution $(3 \mathrm{ng} / \mu \mathrm{l})+V$. dahliae DNA 100-fold dilution $(0.05 \mathrm{ng} / \mu \mathrm{l})$; lane 23, positive control (total genomic DNA extracted from stem of affected olive plants, $30 \mathrm{ng} / \mu \mathrm{l})$; and lane 24 , negative control (water).

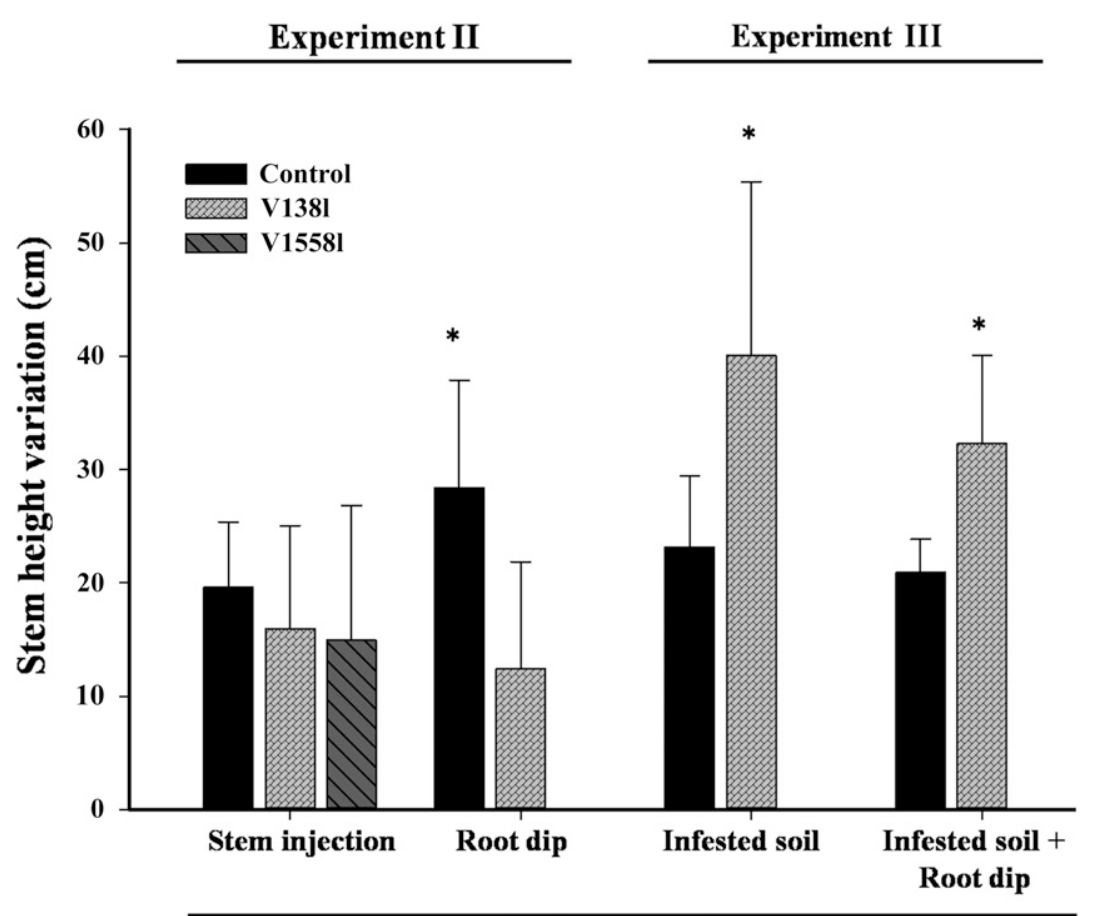

\section{Method of inoculation}

Fig. 3. Effect of inoculation of Paulownia elongata clone PC-2 (experiment II) and P. elongata $\times$ P. fortunei clone PC-3 (experiment III) with olive-defoliating (V138I) and nondefoliating (V1558I) isolates of Verticillium dahliae on plant stem height 57 and 30 weeks after inoculation in experiments II and III, respectively (see text for details). Bars are the mean of 10 replicated plants. Error bars indicate the standard deviation of the mean. An asterisk ( $\left.{ }^{*}\right)$ indicates significant $(P<0.05)$ differences between treatments for the same inoculation method, according to Dunnett's test. 
1999; Jiménez-Díaz et al. 2012; López-Escudero et al. 2004, 2007). Moreover, D V. dahliae was consistently unable to be detected in the stems of inoculated, symptomless paulownia plants. This was indicated by the inability to reisolate the pathogen from stem tissue plated on NP-10 semiselective medium and the lack of amplification of $V$. dahliae DNA using a nested-PCR protocol that had been used successfully to detect the pathogen in olive stem tissue previously (Mercado-Blanco et al. 2003) as well as in this study. However, $V$. dahliae was able to establish incipient infections in paulownia roots, although this ability appeared inconsistent. Isolations from roots were attempted only in experiments II and III, which involved different clones and inoculation methods. $V$. dahliae was reisolated from PC-3 plants that were transplanted into infested soil but not from PC-2 plants that were root-dip inoculated or received stem injections with the pathogen; therefore, either the clone or the inoculation method may influence root infection by $\mathrm{D} V$. dahliae. The prolonged interaction with the fungus in the infested soil mixture may have facilitated infection of the roots, though to a limited extent, as indicated by the mean root colonization index (43.7 to $44.8 \%$ ). Furthermore, infection appeared to be limited to the root cortex, as suggested by the circular pattern of growth of the $V$. dahliae colonies from plated root pieces. Determining the true vascular nature of root infection would have required further microscopy observations that were not carried out in the study.

In our study, we purposely addressed the $\mathrm{D} V$. dahliae pathotype in the VCG1A/D lineage because its high virulence and widespread occurrence in the $1.6 \times 10^{6}$ ha olive-growing area in Andalusia have led to Verticillium wilt being a main threat to olive production in this region (Jiménez-Díaz et al. 2012). Typing of $637 \mathrm{~V}$. dahliae isolates from 433 olive trees in 65 arbitrarily chosen orchards at five provinces of Andalusia in 2005 to 2006 identified the D pathotype in $83.1 \%$ of orchards, with D isolates accounting for $78.1 \%$ of all tested isolates (Jiménez-Díaz et al. 2011). A more recent survey of the D pathotype in Andalusia, which involved 180 arbitrarily chosen affected olive orchards, indicates that this pathotype occurs in the eight provinces of the region with an average prevalence of $82.2 \%$ (37.5 to $100 \%$ ) infected orchards per province (J. A. Navas-Cortés, personal communication). Compared with ND $V$. dahliae, isolates of the D pathotype (i) are more virulent to olive cultivars, (ii) have a much lower threshold of inoculum density for severe disease, and (iii) show a narrower genetic diversity (Jiménez-Díaz et al. 2012; Milgroom et al. 2014). Therefore, demonstrating that the paulownia clones in our study are highly resistant to D V. dahliae would be of much interest as a replacement crop for olive orchards severely infected by the D pathotype in Andalusia.

$V$. dahliae is characterized as having one of the broadest host ranges among fungal plant pathogens, with the term "host" being based on the development of symptoms following infection and colonization of the plant, as traditionally considered in plant pathology. Taken together within this context, results of the present study indicate that paulownia is a highly resistant, symptomless nonhost of D $V$. dahliae, which is a first report of this host for V. dahliae (Hiemstra 1998; Maul 1999; McCain et al. 1981; Pataky 1997; Pegg and Brady 2002). This nonhost characterization is focused on the lack of foliar symptoms on plants of PC-2 and PC-3 clones inoculated with the D isolate. However, there was some stem growth response to inoculation that varied with the clone and method of inoculation, as discussed below, and that was associated with the lack of or limited root infection in PC-2 and PC-3, respectively. The lack of any response of paulownia to stem-injection inoculation with ND $V$. dahliae in our study might also suggest a nonhost resistance response. However, this was only tested in clone PC-2 in a single experiment and must be further confirmed in additional studies using different inoculation procedures, as done for the $\mathrm{D}$ pathotype. The nonhost response of paulownia to the $\mathrm{D}$ pathotype was consistent regardless the several methods of inoculation used in the study, which are known to influence the reaction of herbaceous and woody plants species to $V$. dahliae infection (Cirulli et al. 2008; Palloix et al. 1990; Trapero et al. 2013). Responses of paulownia were consistent in the growth chamber, shade house, and irrigated field microplots, which provided optimal conditions free of abiotic stress. It might be argued that episodic abiotic stress (e.g., drought) in the field might predispose paulownia to more extensive colonization by $\mathrm{D} V$. dahliae that would overcome its apparent resistance, thus resulting in more severe disease expression and limiting the usefulness of paulownia for planting in olive orchards previously affected by this pathogen. However, water stress would be unlikely to play a significant role because olive crops in Andalusia are managed with irrigation and it is likely that subsequent paulownia plantations would also be irrigated as well (Jiménez-Díaz et al. 2012; Lucas Borja et al. 2009) (J. Moreno and J. Requena, unpublished).

Careful studies have shown that plants previously known as $V$. dahliae-symptomless nonhosts can sustain extensive endophytic stem or root colonization, thus raising a new paradigm of the nature of interactions between $V$. dahliae and plants. As a result, it was proposed that plants harboring symptomless endophytic colonization be named symptomless hosts, to be differentiated from true nonhosts, which are symptomless plants that do not interact with the fungus (Malcolm et al. 2013). The confinement of V. dahliae in the plant root system with lack of foliar symptoms found in the present study identifies $P$. elongata $\times P$. fortunei clone PC-3 as a highly resistant symptomless host of D V. dahliae sensu Malcolm et al. (2013). The limited root infection found in symptomless PC-3 paulownia occurred for plants whose root system was interacting with a high inoculum load for 30 weeks. Presumably, those conditions could have facilitated some stem infection which failed to become established over time. Although the incipient nature of the remaining putative infections might have made positive isolation of $V$. dahliae from stems of inoculated plants difficult, the nested-PCR detection assay should had shown the presence of remnants of viable or nonviable $V$. dahliae structures if incipient stem infections had occurred. Conversely, paulownia clone PC-2 can be considered a true nonhost of D V. dahliae sensu Malcolm et al. (2013) based on the lack of foliar symptoms and infection in the plant. Because the range of symptomatic and symptomless hosts plants of $V$. dahliae seems to be limited to dicotyledonous and monocotyledonous plants, respectively (Malcolm et al. 2013), P. elongata PC-2 would be the first dicotyledonous woody tree nonhost of $V$. dahliae.

Symptomless root infection of PC-3 paulownia in soil infested with the $\mathrm{D} V$. dahliae significantly enhanced stem growth but a reverse effect was observed in PC-2 plants that were root-dip inoculated with the same pathogen strain. No conclusion can be derived from these effects because there were two factors involved; namely, the nature of the paulownia and the method of inoculation. Yet, infection by $V$. dahliae has the potential of enhancing growth of Verticillium wilt-tolerant tomato cultivars following root dip inoculation that resulted in extensive stem colonization by the pathogen (Robb et al. 2007). More research is needed to sort out whether growth enhancement of paulownia by $V$. dahliae is mediated by the continuous fungus-root interaction or the nature of the clone.

The symptomless host and nonhost resistance to $\mathrm{D} V$. dahliae shown by Paulownia spp. in this present study may have important practical applications in the use of fertile soils in Andalusia (southern Spain) highly infested with this pathotype (Jiménez-Díaz et al. 2011), as well as a replacement crop for olive orchards severely affected by Verticillium wilt in that region. In addition, Paulownia spp. would be an interesting plant model system for unraveling plant defense mechanisms underlying complete resistance to $V$. dahliae.

\section{Acknowledgments}

Financial support for this research was provided by grants P10-AGR 6082 from CICE-Junta de Andalucía, Spain and IDI-20120047 from CEDETI, Ministerio de Economía y Competitividad of Spain. We thank P. Castillo, B. B. Landa, and J. A. Navas for critically reading the manuscript and making valuable suggestions.

\section{Literature Cited}

Bassett, S. 1998. Paulownia: A Commercial Overview. Rural Industry Business Services, Department of Primary Industries, Queensland, Australia.

Bejarano-Alcázar, J., Blanco-López, M. A., Melero-Vara, J. M., and JiménezDíaz, R. M. 1996. Etiology, importance, and distribution of Verticillium wilt of cotton in southern Spain. Plant Dis. 80:1233-1238.

Bhat, R. G., and Subbarao, K. V. 1999. Host range specificity in Verticillium dahliae. Phytopathology 89:1218-1225. 
Cirulli, M., Colella, C., D’Amico, M., Amenduni, M., and Bubici, G. 2008. Comparison of screening methods for the evaluation of olive resistance to Verticillium dahliae Kleb. J. Plant Pathol. 90:7-14.

Collado-Romero, M., Mercado-Blanco, J., Olivares-García, C., ValverdeCorredor, A., and Jiménez-Díaz, R. M. 2006. Molecular variability within and among Verticillium dahliae vegetative compatibility groups determined by fluorescent amplified fragment length polymorphism and polymerase chain reaction markers. Phytopathology 96:485-495.

Hiemstra, J. A. 1998. Some general features of Verticillium wilts in trees. Pages 5-11 in: A Compendium of Verticillium Wilt in Tree Species. J. A. Hiemstra and D. C. Harris, eds. Posen and Looijen, Wageningen, The Netherlands.

Hiruki, C. 1999. Paulownia witches'-broom disease important in East Asia. Acta Hortic. 469:63-68.

Hoagland, D. R., and Arnon, D. I. 1950. The water culture method for growing plants without soil. Calif. Agric. Exp. Stn. Circ. No. 347.

Inderbitzin, P., Bostock, R. M., Davis, R. M., Usami, T., Platt, H. W., and Subbarao, K. V. 2011. Phylogenetics and taxonomy of the fungal vascular wilt pathogen Verticillium, with the descriptions of five new species. PLoS One 6:e28341.

Jiménez-Díaz, R. M., Cirulli, M., Bubici, G., Jiménez-Gasco, M. M., Antoniou, P. P., and Tjamos, E. C. 2012. Verticillium wilt: A major threat to olive production. Current status and future prospects for its management. Plant Dis. 96:304-329.

Jiménez-Díaz, R. M., Mercado-Blanco, J., Olivares-García, C., Collado-Romero, M., Bejarano-Alcázar, J., Rodríguez-Jurado, D., Giménez-Jaime, A., GarcíaJiménez, J., and Armengol, J. 2006. Genetic and virulence diversity in Verticillium dahliae populations infecting artichoke in eastern-central Spain. Phytopathology 96:288-298.

Jiménez-Díaz, R. M., Olivares-García, C., Navas-Cortés, J. A., Landa, B. B., and Jiménez-Gasco, M. M. 2011. A region-wide analysis of genetic diversity in Verticillium dahliae infecting olive in southern Spain and agricultural factors influencing the distribution and prevalence of vegetative compatibility groups and pathotypes. Phytopathology 101:304-315.

Jiménez-Fernández, D., Montes-Borrego, M., Navas-Cortés, J. A., Jiménez-Díaz, R. M., and Landa, B. B. 2010. Identification and quantification of Fusarium oxysporum in planta and soil by means of an improved specific and quantitative PCR assay. Appl. Soil Ecol. 46:372-382.

Kabir, Z., Bhat, R. G., and Subbarao, K. V. 2004. Comparison of media for recovery of Verticillium dahliae from soil. Plant Dis. 88:49-55.

Landa, B. B., Montes-Borrego, M., Muñoz-Ledesma, F. J., and Jiménez-Díaz, R. M. 2007. Phylogenetic analysis of downy mildew pathogens of opium poppy and PCR-based in planta and seed detection of Peronospora arborescens. Phytopathology 97:1380-1390.

López-Escudero, F. J., Blanco-López, M. A., del Río, C., and Caballero, J. M. 2007. Response of olive cultivars to stem puncture inoculation with a defoliating pathotype of Verticillium dahliae. HortScience 42:294-298.

López-Escudero, F. J., del Río, C., Caballero, J. M., and Blanco-López, M. A. 2004. Evaluation of olive cultivars for resistance to Verticillium dahliae. Eur. J. Plant Pathol. 110:79-85.

Lucas Borja, M. E., Martínez García, E., López Serrano, F. R., Andrés Abellán, M., García Morote, F. A., and Candel Pérez, D. 2009. El Cultivo Forestal de Paulownia spp.: Primeros Resultados de su Aplicación en Castilla La
Mancha. In: Escuela Técnica Superior de Ingenieros Agrónomos. Universidad de Castilla la Mancha, Albacete, Spain. (In Spanish)

Lyons, A. 1993. Paulownia. Pages 149-154 in: Agroforestry, Trees for Productive Farming. D. Race, ed. Agmedia, Victoria, Spain.

Malcolm, G. M., Kuldau, G. A., Gugino, B. K., and Jiménez-Gasco, M. M. 2013 Hidden host plant associations of soilborne fungal pathogens: An ecological perspective. Phytopathology 103:538-544.

Maul, J. 1999. Southwestern Oregon Tree Selection Guide, EC 1505. Oregon State University Extension Service, Oregon State University, Corvallis, OR.

McCain, A. H., Raabe, R. D., and Wilhelm, S. 1981. Plants Resistant or Susceptible to Verticillium Wilt. Leaflet 2703. Department of Plant Pathology, University of California, Berkeley.

Mehrotra, M. D. 1997. Diseases of paulownia and their management. Ind. For 123:66-72.

Mercado-Blanco, J., Rodríguez-Jurado, D., Parrilla-Araujo, S., and Jiménez-Díaz, R. M. 2003. Simultaneous detection of the defoliating and nondefoliating Verticillium dahliae pathotypes in infected olive plants by duplex, nested polymerase chain reaction. Plant Dis. 87:1487-1494.

Mercado-Blanco, J., Rodríguez-Jurado, D., Pérez-Artés, E., and Jiménez-Díaz, R. M. 2002. Detection of the defoliating pathotype of Verticillium dahliae in infected olive plants by nested PCR. Eur. J. Plant Pathol. 108:1-13.

Milgroom, M. G., Jiménez-Gasco, M. M., Olivares-García, C., Drott, M. T., and Jiménez-Díaz, R. M. 2014. Recombination between clonal lineages of the asexual fungus Verticillium dahliae detected by genotyping by sequencing. PLoS One 9, 9:e106740.

Navas-Cortés, J. A., Landa, B. B., Mercado-Blanco, J., Trapero-Casas, J. L., Rodríguez-Jurado, D., and Jiménez-Díaz, R. M. 2008. Spatiotemporal analysis of spread of Verticillium dahliae pathotypes within a high tree density olive orchard in southern Spain. Phytopathology 98:167-180.

Nene, Y. L., and Haware, M. P. 1980. Screening chickpea for resistance to wilt. Plant Dis. 64:379-380.

Palloix, A., Pochard, E., Phaly, T., and Daubèze, A. M. 1990. Recurrent selection for resistance to Verticillium dahliae in pepper. Euphytica 47:79-89.

Pataky, N. R. 1997. Verticillium Wilt Disease RPD No. 1010. Department of Crop Sciences, University of Illinois, Urbana-Champaign.

Pegg, G. F., and Brady, B. L. 2002. Verticillium Wilts. CABI Publishing, New York.

Robb, J., Lee, B., and Nazar, R. N. 2007. Gene suppression in a tolerant tomatovascular pathogen interaction. Planta 226:299-309.

Talboys, P. W. 1960. A culture medium aiding the identification of Verticillium albo-atrum and V. dahliae. Plant Pathol. 9:57-58.

Trapero, C., Díez, C. M., Rallo, L., Barranco, D., and López-Escudero, F. J. 2013. Effective inoculation methods to screen for resistance to Verticillium wilt in olive. Sci. Hortic. 162:252-259.

White, T. J., Bruns, T., Lee, S., and Taylor, J. W. 1990. Amplification and direct sequencing of fungal ribosomal RNA genes for phylogenetics. Pages 315-322 in: PCR Protocols: A Guide to Methods and Applications. M. A. Innis, D. H. Gelfand, J. J. Sninsky, and T. T. White, eds. Academic Press Inc., New York.

Wilhelm, S. 1955. Longevity of Verticillium wilt fungus in the laboratory and field. Phytopathology 45:180-181.

Zhu, Z. H., Chao, C. J., Lu, X. Y., and Xiong, Y. G. 1986. Paulownia in China: Cultivation and Utilization. Asian Network for Biological Sciences and International Development Research Center, Beijing. 